\title{
Effect the Temperature on Structure and Optical Properties for ZnS nanostructure Thin Film
}

\author{
Nada K. Abbas, Khalid T. Al- Rasoul, Zainab J. Shanan, Naan F. Majeed \\ College of science for Women, University of Baghdad, Jadriya, Baghdad, Iraq \\ E-mail: nadabbsh@yahoo.com \\ College of science, University of Baghdad, Jadriya, Baghdad, Iraq \\ College of science for Women, University of Baghdad, Jadriya, Baghdad, Iraq \\ E-mail: zainabjassim73@yahoo.com \\ College of science for Women, University of Baghdad, Jadriya, Baghdad, Iraq
}

\begin{abstract}
ZnS nanocrystalline thin films by different temperature of reaction were prepared by chemical bath deposition using thiourea and zinc acetate as $\mathrm{S}^{2-}$ and $\mathrm{Zn}^{2+}$ source. The optical absorption studies in the wavelength range 200-1100 nm show that band gap energy of samples 3.75 and $4.0 \mathrm{eV}$ for different temperature reaction condition. The refractive index was estimated within the visible wavelength at $623 \mathrm{~nm}$, it was 2.04 for sample 1 and its value will increase for sample 2 to be 2.55. The room temperature photoluminescence spectra of the films showed two peaks for all samples. We assigned the first peak due to band gap transitions while the latter was due to zinc vacancy in the films. Structural analysis using atomic force microscopy shows that the grain size for films were 73.2 and $87.34 \mathrm{~nm}$. X-ray diffraction analysis indicates that both of them formed in the reaction bath have cubic zinc blende structure. The structural estimation shows variation in grain size $7 \mathrm{~nm}$ and $20 \mathrm{~nm}$ with different temperature reaction.
\end{abstract}

Keywords: Nanocrystalline; ZnS; CBD method; optical properties

\section{Council for Innovative Research}

Peer Review Research Publishing System

\section{Journal: Journal of Advances in Chemistry}

Vol. 11, No. 2

editorjaconline@gmail.com

www.cirjac.com 


\section{INTRODUCTION}

In the past few decades, metal chalcogenides have been extensively studied because of their important physical chemical properties and their great potential application in electronic, optical, and superconductor devices [1-4].

Nanostructured materials have attracted a great deal of attention for their unique characteristics that cannot be obtained from conventional macroscopic materials. Owing to quantum size effects and surface effects, nanoparticles can display novel optical, electronic, magnetic, chemical, and structural properties that might find many important technological applications. An extremely active and prolific field in nanomaterials is finding ways to control size and morphology of the nanoparticles since the properties and applications of the nanoparticles are largely dependent on their size and morphology. The most evident manifestation of properties is the optical light emission in the blue - red spectral region characterized by a blue-shift at smaller crystallite dimensions [5].

ZnS nanoparticles show special photo electricity properties, such as photoluminescence (PL) and electroluminescence (EL) [6-7], thus they have extensive application in lasers, sensors, infrared windows, displays, and many other fields [8-11]. ZnS particles have two kinds of structures: zinc blende structure (cubic crystal) and wurtzite structure (hexahedron). ZnS applied in luminescent materials generally has zinc blende structure[12]. There are many methods to prepare ZnS nanoparticles, which can be divided into two categories: physical method and chemical method. The chemical method mainly includes thermal decomposition method, micro-emulsion method, sol-gel method, and LB technique. However, these methods need high reaction temperature, vast use of organic solvents, high cost of equipment operation, and complex process control. In most cases, particles prepared by these methods are of poor uniformity and agglomerate easily [13-14].

Chemical bath deposition is a well known deposition process for some chalcogenides such as $\mathrm{Zn}, \mathrm{Co}, \mathrm{Cd}, \mathrm{Hg}, \mathrm{Pb}$, sulphides and selenides. Zinc sulfide is an important semiconductor material with large band gap ( $3.5 \mathrm{eV})$, high refractive index (2.35 at $632 \mathrm{~nm})$, high effective dielectric constant (9 at $1 \mathrm{MHz})$ and wide wavelength pass band $(0.4-13 \mu \mathrm{m})$. Its optical properties make it useful as a filter, reflector and planar wave guide. $[15,16]$

\section{EXPERIMENTAL}

\subsection{Sample 1}

A chemical bath deposition (CBD) method was employed to deposit ZnS thin films onto glass substrates using thiourea as sulfide ion source and zinc acetate as zinc ion source in alkaline bath. For the preparation of ZnS thin films, $0.1 \mathrm{M}$ zinc acetate solution was taken in a beaker and an equal volume of $0.1 \mathrm{M}$ thiourea solution was added. Ammonia solution was added slowly to form the complex and $\mathrm{pH}$ was adjusted between 9 and 10 . The solution was stirred for a few seconds and transferred to another beaker containing glass substrates. The solution was kept at room temperature for three hours.

\subsection{Sample 2}

We use the same method and conditions but the reaction was done at $70^{\circ} \mathrm{C}$. The deposition process is based on the slow release of $\mathrm{Zn}^{2+}$ and $\mathrm{S}^{2-}$ ions in solution which then condense on the substrate .

The deposition of $\mathrm{ZnS}$ occurs when the ionic product of $\mathrm{Zn}^{+}$and $\mathrm{S}^{2-}$ exceeds the solubility product of $\mathrm{ZnS}$.

Ammonia forms a complex ion with $\mathrm{Zn}^{2+}$

The complex then reacts with sulfide ions to form $\mathrm{ZnS}$.

$$
\mathrm{Zn}\left(\mathrm{NH}_{3}\right)_{4}^{+2}+\mathrm{S}^{2-} \leftrightarrow \mathrm{ZnS}+4 \mathrm{NH}_{3}
$$

The grain size calculations were carried out by using XRD studies on a Philips X-ray Diffract meter. Fizzau's method was used to measure the thickness for samples. The optical absorption studies were carried out using SP-3000 plus, OPTIMA INC., Japan, to calculate optical band gap and grain size for samples. The PL spectrum of ZnS thin films has been measured at room temperature using Hitachi F-2500 FL Spectro-photometer. The excitation wavelength was $250 \mathrm{~nm}$ for all samples. To study the morphological characteristics and surface roughness of ZnS thin films, surface morphology photographs were recorded by using (CSPM AA3000 AFM) supplied by Angstrom Advanced Ins., USA. 


\section{RESULTS AND DISCUSSION}

\subsection{Structural Studies}

The XRD patterns of the samples at different reaction conditions are given in (Figures 1,2) and all diffraction peaks can be conclusively indexed as cubic Zinc blend (Joint Committee on Powder Diffraction Standards (JCPDS) card: 65-0309), indicating that the as-prepared sample is of high quality. From the XRD peak intensity and shapes in ( Figure 1), it can be inferred that the quality of crystal increased with different temperature reaction, but the grain size of particles was decrease.

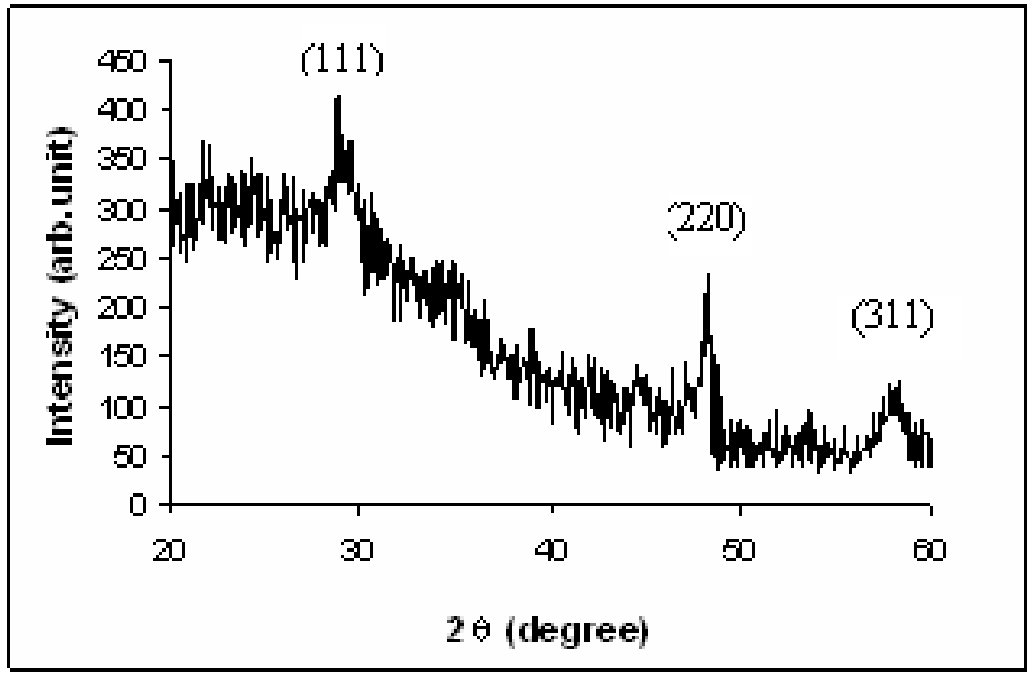

Fig.1: The XRD patterns of as-prepared Sample1 nanocrystalline

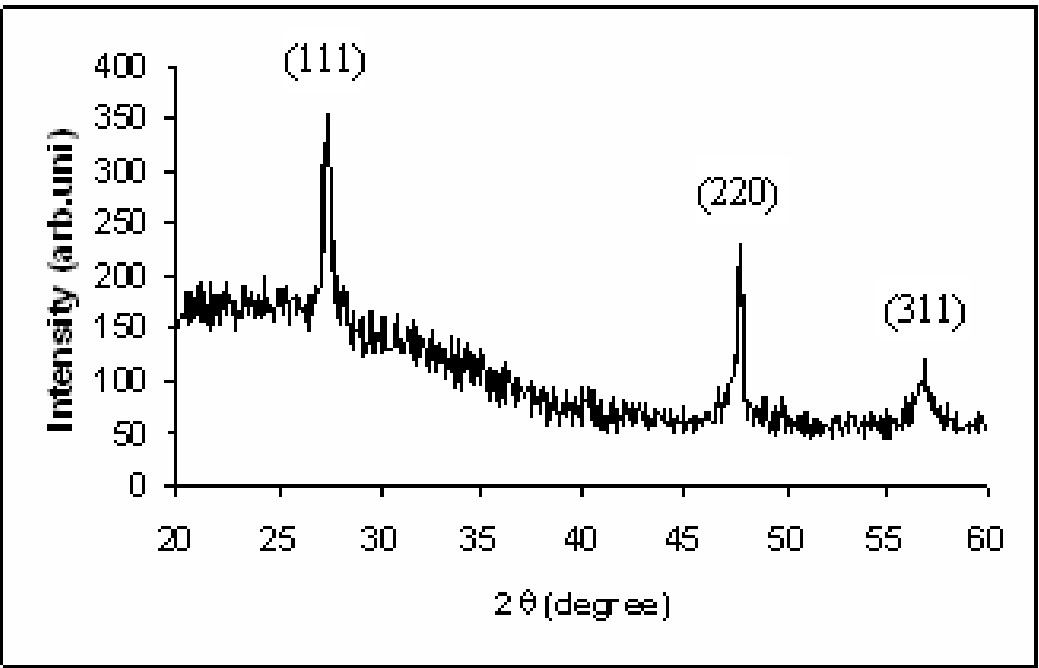

Fig. 2: The XRD patterns of as-prepared Sample 2 nanocrystalline

The crystallite size is calculated using Scherrer's formula [16]

$$
d=\lambda / \beta \cos \theta
$$

Where $\lambda$ is the wavelength used (1.54 $\AA$ ), $\beta$ is the broadening of diffraction line measured at full width of half maximum intensity (FWHM) in radians and $\theta$ the Bragg's angle. The grain size for sample 1 was $\sim 7 \mathrm{~nm}$ while for sample 2 equal 20nm. 


\subsection{Surface Morphological Studies}

Atomic force microscopic (AFM) allows us to get microscopic information on the surface structure and to plot topographies representing the surface relief. This technique offers digital images which allow quantitative measurements of surface features, such as root mean square roughness, $R q$, or average roughness $R a$, and the analysis of images from different perspectives, including three-dimensional simulation [17].AFM images of two films are shown in( Figures 3 and 4) for two and three dimensions.
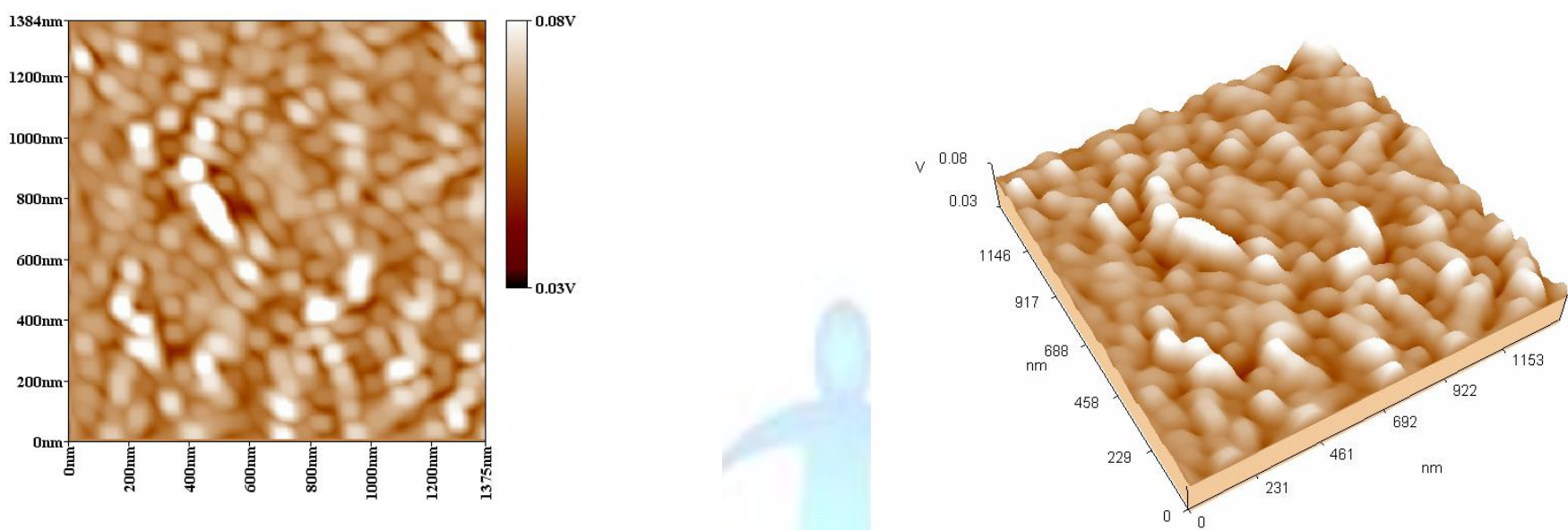

Fig.3 AFM images of Sample 1 thin film. (a) Two-dimensional and (b) Three - dimensional.

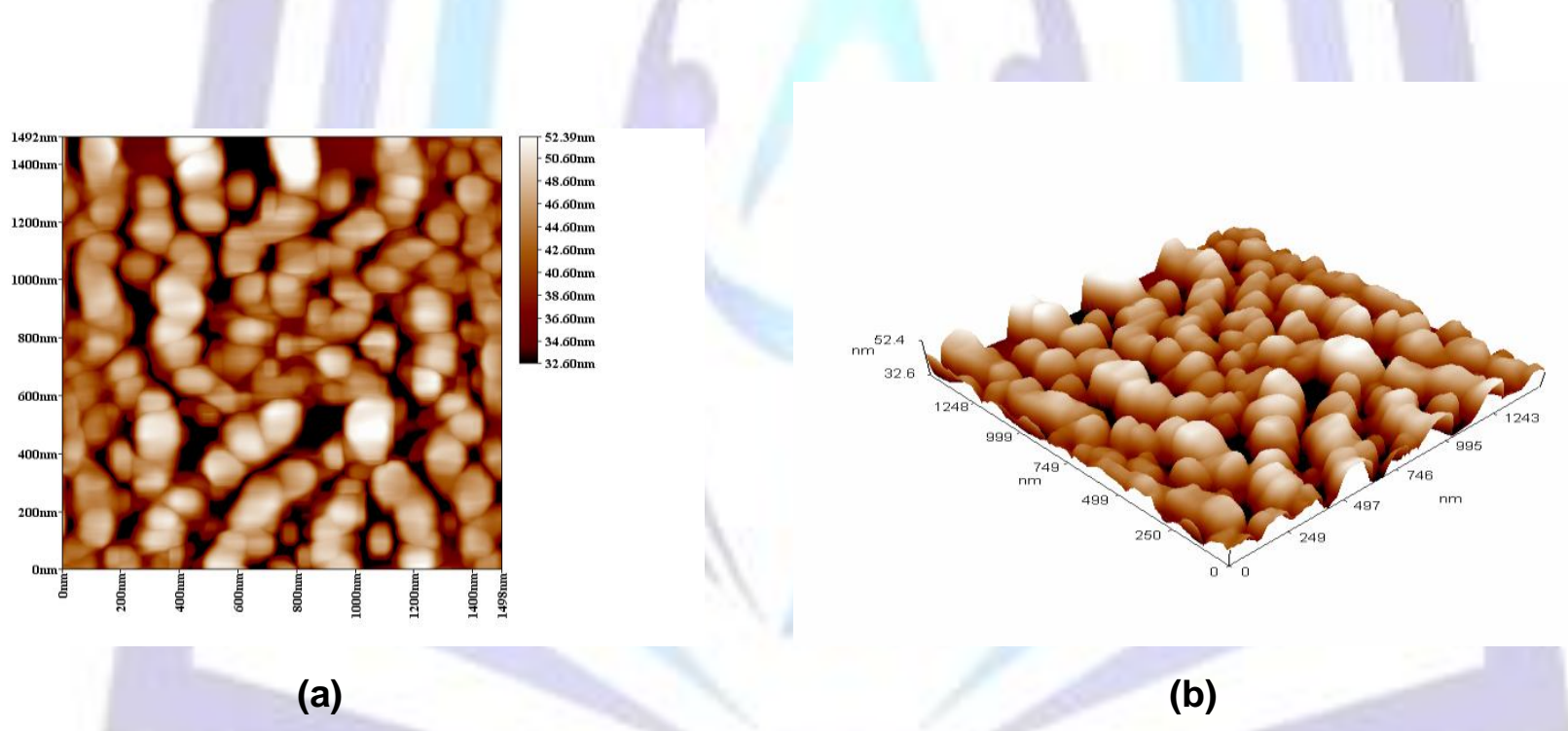

Fig. 4 AFM images of Sample2 thin film (a) Two-dimensional and (b) Three - dimensional.

The sample 2 is made of semi spherical grains with high vacancy compared with sample1 which appears more closed. Therefore density for sample1 more than sample2 whereas grain boundaries for sample2 it's very clearly. As observable, the sample1 film contains smaller clusters (average grain size $73.2 \mathrm{~nm}$ in diameter) and has more surface aggregates than the sample2 (average grain size of $87.34 \mathrm{~nm}$ in diameter), because of temperature occur increase for growth the particles. These results agree with XRD measurements. Smooth and regular surfaces are observed on sample 2 . The root mean square roughness $(R q)$ and the average roughness $(R a)$ for sample 1 were found to be $4 \mathrm{~nm}$ and $5 \mathrm{~nm}$, respectively. For the sample 2 , it is calculated $R q$ and $R a$ values of $6.73 \mathrm{~nm}$ and $8.76 \mathrm{~nm}$, respectively. It is important to note that these obtained values are averaged and there is a statistical variation associated with them, which depends on the location of the measurements that are performed on the samples [17]. To minimize these errors, we have performed many measurements of each parameter in different locations on the surface of samples.

\subsection{Optical Properties}

The optical properties of ZnS thin film prepared by different reaction deposition is determined from absorbance measurement in the range $200-1100 \mathrm{~nm}$ (see Figures 5 and 6) show the absorption spectra of sample 1 and sample2 thin film respectively. 


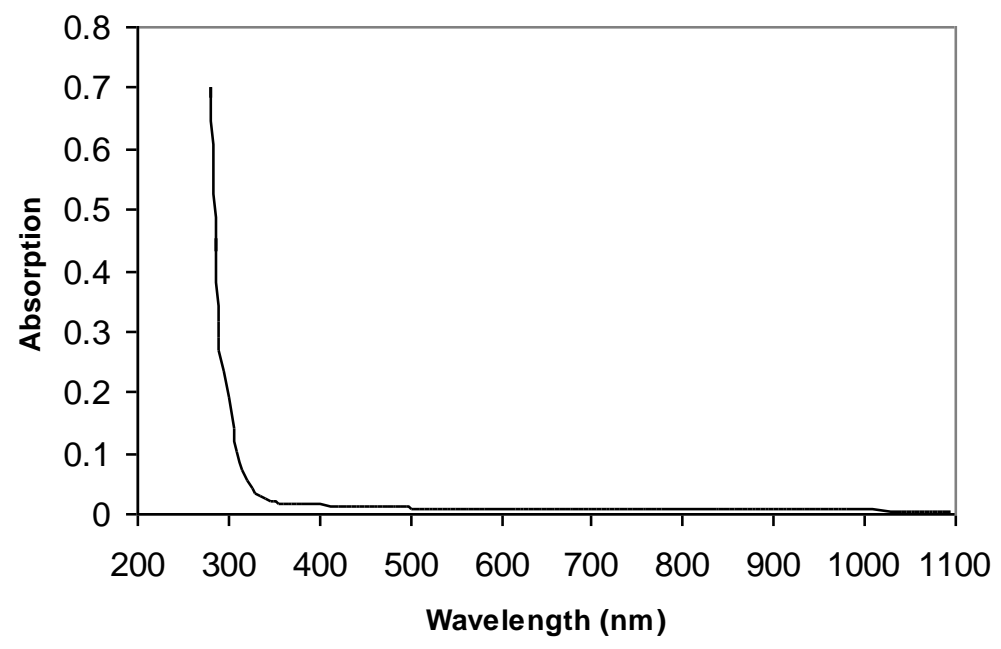

Fig. 5 UV-Vis absorption spectra of sample1 thin film
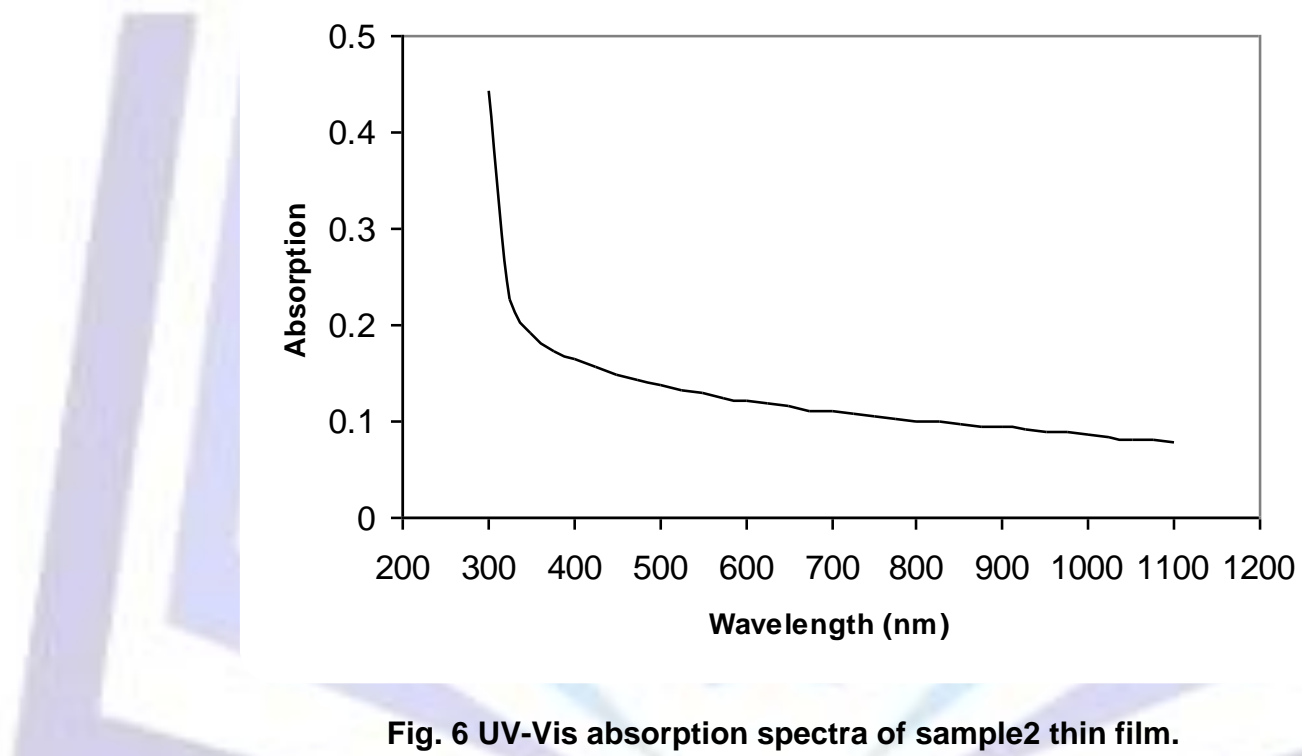

Fig. 6 UV-Vis absorption spectra of sample2 thin film.

Absorbance coefficient $\alpha$ associated the strong absorption region of the film was calculated from absorbance $(A)$ and the film thickness (t) using relation $[18,19]$

$$
\alpha=2.3026 \mathrm{~A} / \mathrm{t} \text {. }
$$

Where the thickness of sample1 was $142 \mathrm{~nm}$ while for sample 2 was $120 \mathrm{~nm}$. The absorption coefficient $\alpha$ was analyzed using the following expression for optical absorption of semiconductors [20]

$$
(\alpha h v)=A(h v-E g)^{n / 2}
$$

Where $\mathrm{A}$ is constant, Eg is separation between valence and conduction bands and $\mathrm{n}$ is constant that is equal to 1 for direct band gap semiconductor. 


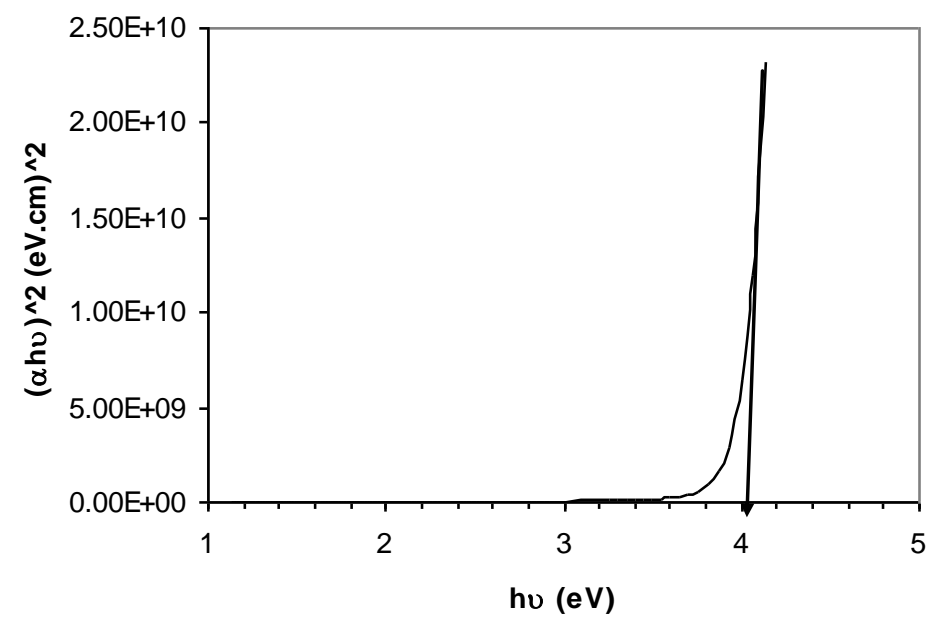

Fig. 7: Band gap determination of sample1

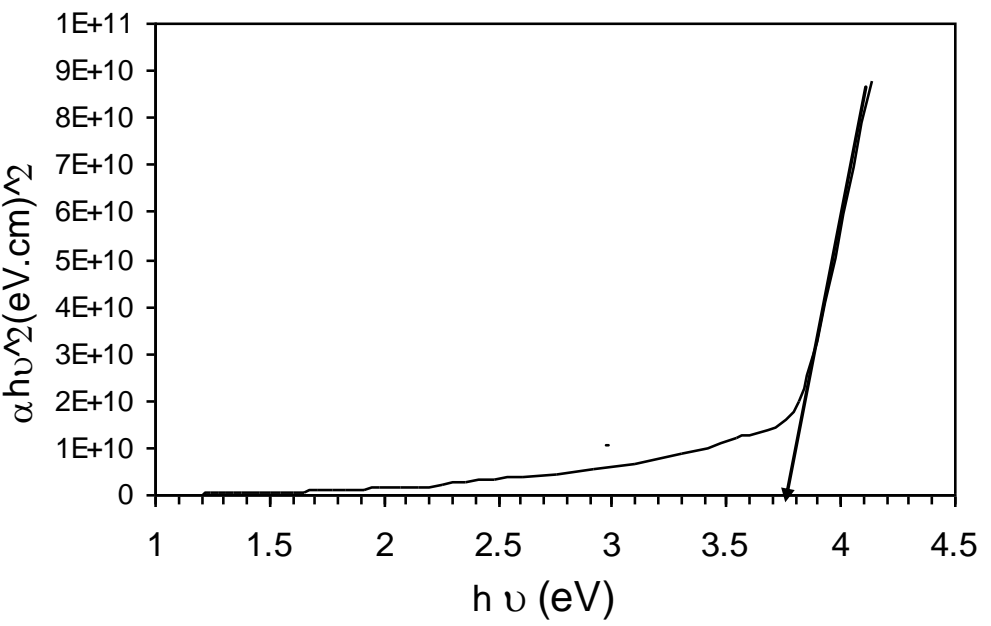

Fig.8: Band gap determination of sample 2

The band gap values were determined from the intercept of the straight-line portion of the $(\alpha h v)^{2}$ against the $h v$ graph on the hv-axis using computer fitting program (Figs. 7 and 8).

The linear part shows that the mode of transition in these films is of direct nature. The calculated band-gap value of the sample 1 was $\sim 4.0 \mathrm{eV}$ and sample 2 was $\sim 3.75 \mathrm{eV}$. The band-gap values are higher than bulk value of ZnS $(3.68 \mathrm{eV})$ because of quantum confinement of ZnS nanocrystals. The absorption spectra (Figures.4,5) reveal that the excitonic absorption peaks for nanocrystal are blue shifted compared to the bulk band gap (3.68 eV corresponding to the absorption edge at $336 \mathrm{~nm}$ ) and clearly indicate strong quantum size effect. The average particle size present in the nanocolloid can be determined by using the mathematical model of effective mass approximation [5]

$$
\Delta \mathrm{Eg}=\left[\mathrm{h} 2 / 8 \mu \mathrm{r}^{2}\right]-1.8 \mathrm{e}^{2} / \varepsilon_{0} \varepsilon_{\mathrm{r}} \mathrm{r}
$$

where $1 / \mu=1 / m_{\mathrm{e}}{ }^{*}+1 / m_{\mathrm{h}}{ }^{*}$ is the reduced mass of electron hole effective mass, $m_{\mathrm{e}}{ }^{*}=0.34 m_{0}$ and $m_{\mathrm{h}}{ }^{*}=0.23 m_{0}$ and $\varepsilon_{\mathrm{r}}=$ $8: 76$ is the permittivity of the sample.

The above equation derived, describes the particle size ( $r$, radius) as a function of peak absorbance wavelength $(\lambda p)$ for ZnS nanocrystals [21]. 


$$
r(n m)=\left[\left\{-0.2963+\left(-40.1970+13620 / \lambda_{p}\right)^{1 / 2}\right\} /\left\{-7.34+2481.6 / \lambda_{p}\right\}\right]^{\wedge} 2 \ldots \text { (4) }
$$

The particle size obtained from optical and structure properties showed in ( table 1).

Table: (1) particle size obtained from optical and structure properties

\begin{tabular}{|c|c|c|c|}
\hline Type of sample & $\begin{array}{c}\text { Particle size } \\
\text { from AFM } \\
(\mathbf{n m})\end{array}$ & $\begin{array}{c}\text { Particle size } \\
\text { from X-ray } \\
\text { diffraction } \\
\text { (nm) }\end{array}$ & $\begin{array}{c}\text { Particle size } \\
\text { from optical } \\
\text { properties (nm) }\end{array}$ \\
\hline Sample 1 & 73.2 & 7 & 5.4 \\
\hline Sample 2 & 87.34 & 20 & 14 \\
\hline
\end{tabular}

\subsubsection{Transmission Spectra}

(Figures 9,10) show the transmission spectra of ZnS film at sample1 and sample2 respectively.

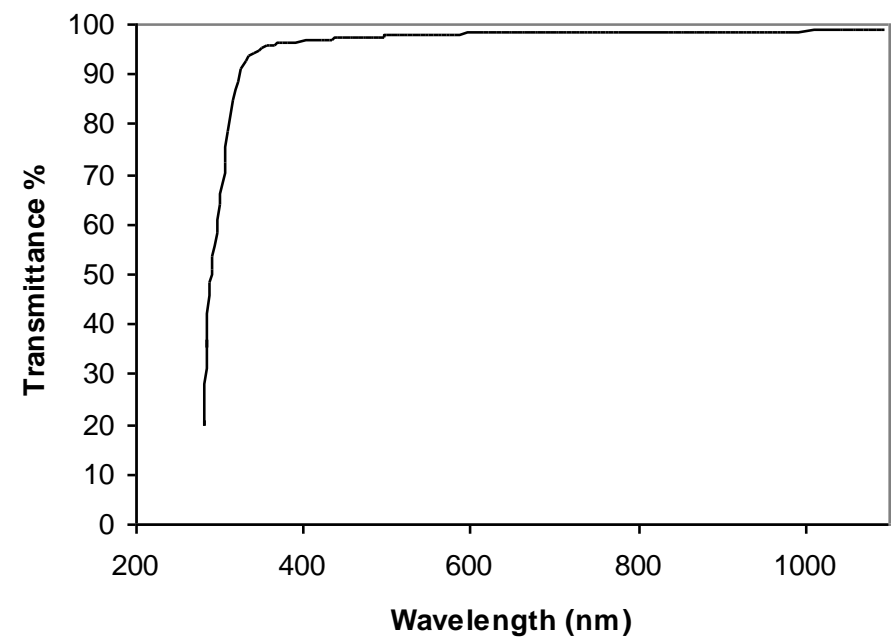

Fig. 9: The transmission spectra of sample1 thin film 


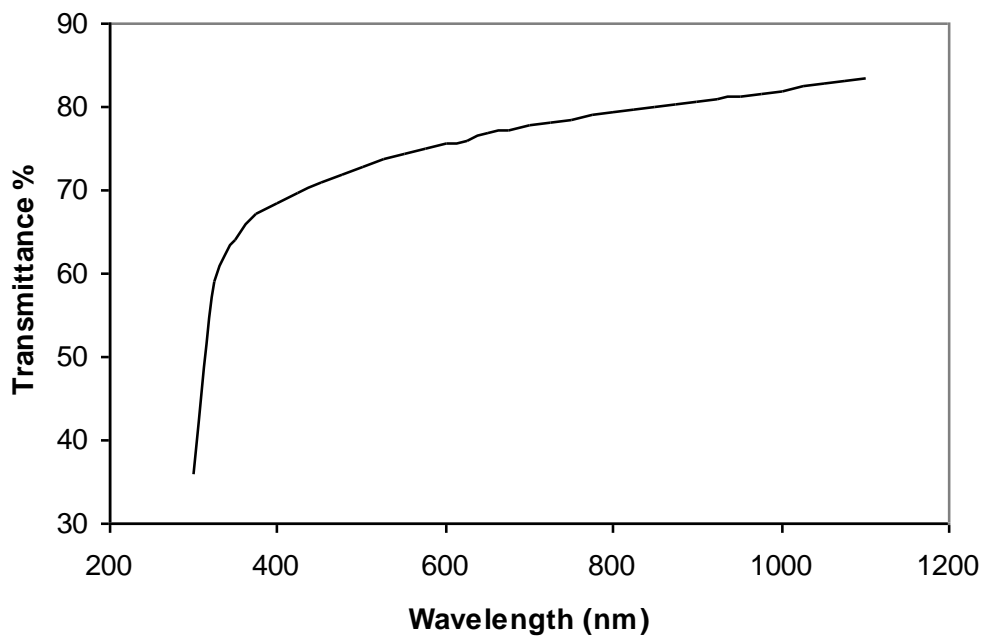

Fig. 10: The transmission spectra of sample2 thin film

It can be observed that above the 400nm wavelength the transmittance of the samples high and lie between 70-95 \% .The different in transmittance attributed to the improvement in crystalline in the film (sample2) which deposited at $70^{\circ} \mathrm{C}$. Sample1 makes it a good material for optoelectronic devices as a window layer, while sample 2 makes it a good material for optoelectronic devices as a absorption layer.

\subsubsection{Extinction Coefficient}

The extinction coefficient $(k)$ can be determined from the absorbance measurements as a function of the wavelength within the range $300-1100 \mathrm{~nm}$; it was calculated by using the following equation:

$$
k=\alpha \lambda / 4 \pi
$$

where $\lambda$ is the wavelength. Extinction coefficient versus wavelength spectra is shown in (Figures 10, 11), there is a little decreasing in the extinction coefficient in the visible range; $(400-700) \mathrm{nm}$, then the rapid rise appeared within the range $300-400 \mathrm{~nm}$.

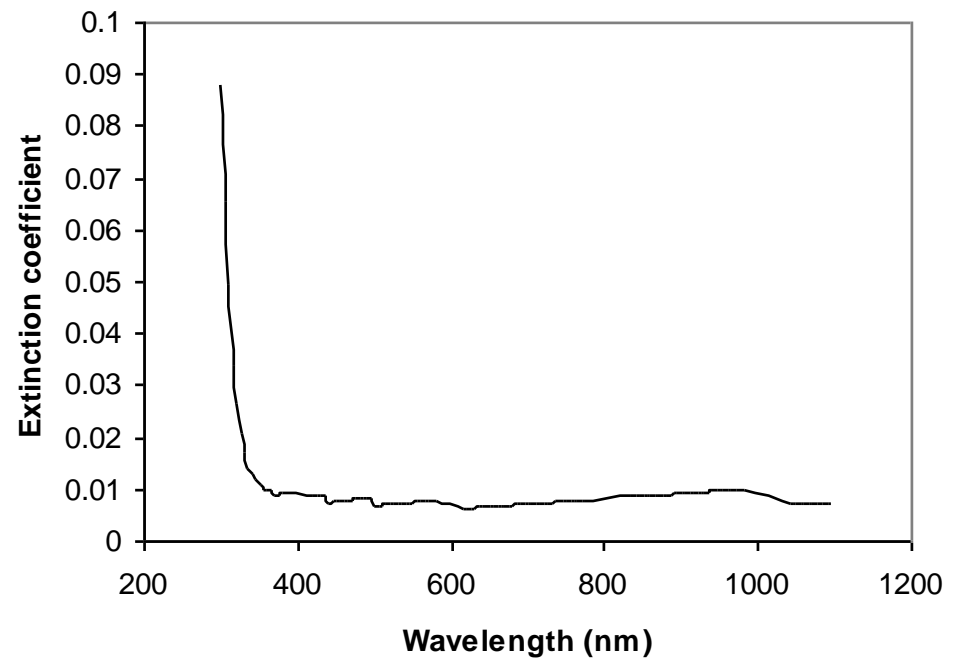

Fig. 11: The extinction coefficient of sample1 thin film 


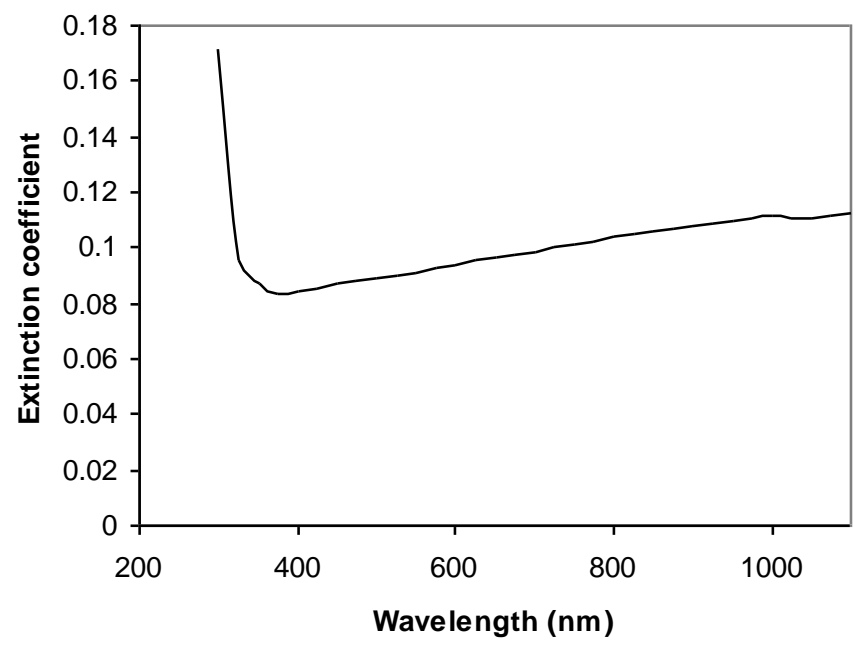

Fig. 12: The extinction coefficient of sample2 thin film

The increased extinction coefficient at the wavelengths below $400 \mathrm{~nm}$ is due to the high absorbance of $\mathrm{ZnS}$ thin films in that region.

\subsubsection{Refractive index}

The refractive index of material is the key parameter for device design. In semiconductor the evaluation of refractive indeces is of considerable importance for applications in integrated optics [22].

The refractive index $(n)$ was determined from a transmittance spectrum as a function of the photon energy within the wavelength in the range $200-1100 \mathrm{~nm}$. The refractive index (n) can be determined by using equation

$$
n=\left[(4 R /(R-1) 2)-K^{2}\right] 1 / 2-[(R+1) /(R-1)]
$$

The refractive index of the prepared film for sample1 was calculated in the visible region, it was $\sim 2.041$ at wavelength $623 \mathrm{~nm}$, and sample2 was $\sim 2.55$ at wavelength $623 \mathrm{~nm}$ as shown in (Figures 13,14 ). The value of the refractive index is in good agreement to the reported value which is 2.35 in the visible range $[23,24]$.

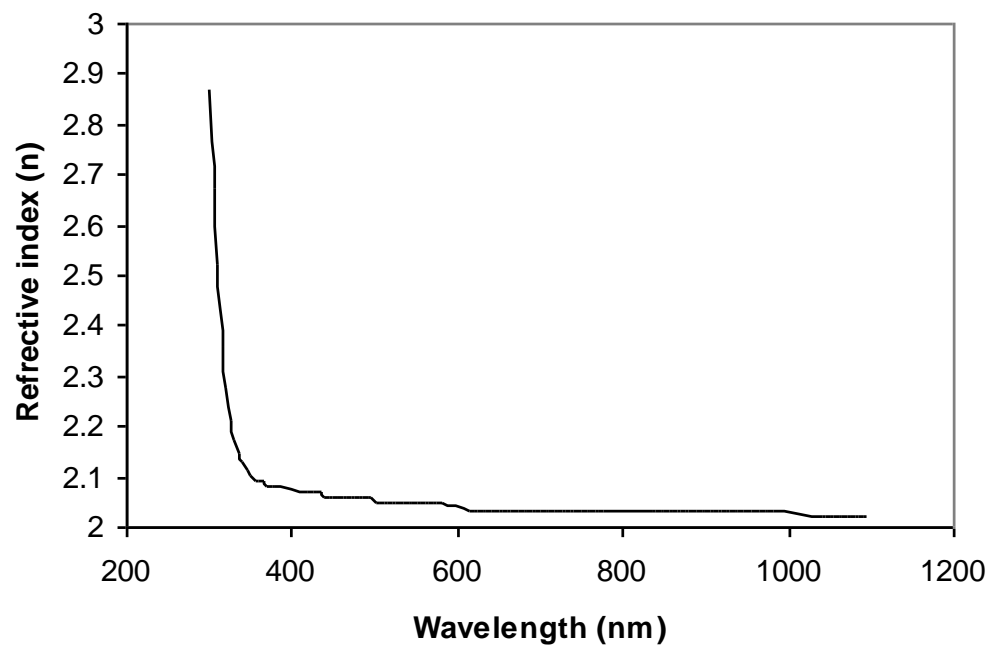

Fig.13: The refractive index of sample1 thin films 


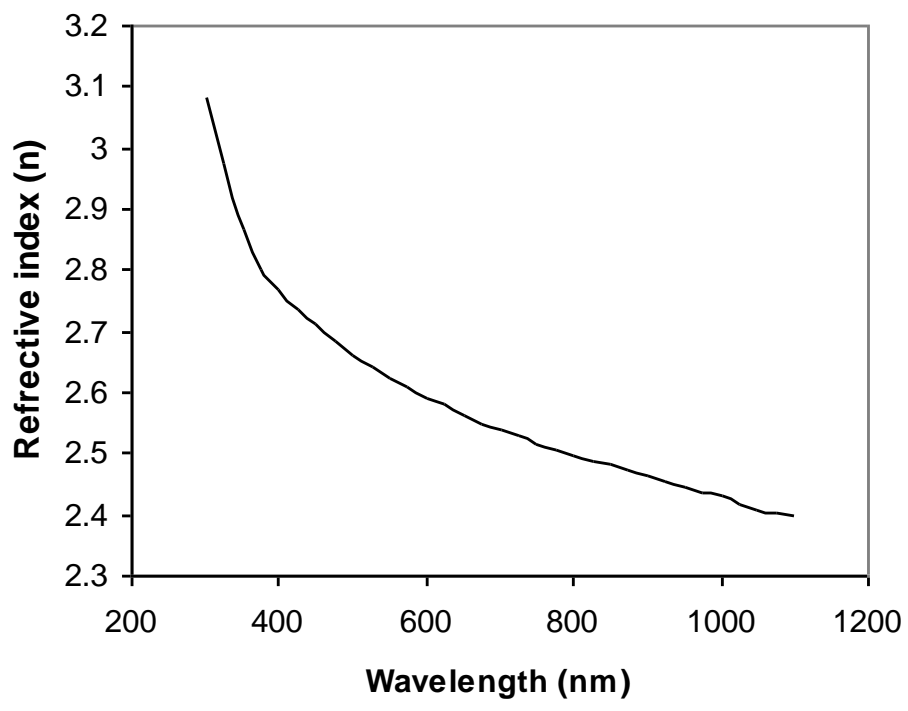

Fig.14: The refractive index of sample2 thin films

\subsubsection{The Dielectric Constant $\left(\boldsymbol{E}_{\mathbf{r}} \boldsymbol{\&} \boldsymbol{E}_{\mathbf{i}}\right)$}

The real parts of dielectric constant $(\varepsilon r)$ can be calculated from the relation:

$$
\varepsilon_{r}=n^{2}-k^{2}
$$

The imaginary parts of dielectric constant $(\varepsilon i)$ can be calculated from the relation

$$
\varepsilon_{\mathrm{i}}=2 \mathrm{nk}
$$

Where $\mathrm{n}$ is representing as the refractive index, $\mathrm{k}$ is the extinction coefficient.

(Figures 15, 16) show the plot $\varepsilon$ i against the wavelength. From the (Figures.15, 16) we can observe that the real part of dielectric constant decreases with increasing $(\lambda)$. This behavior is similar to the behavior of the refractive index.

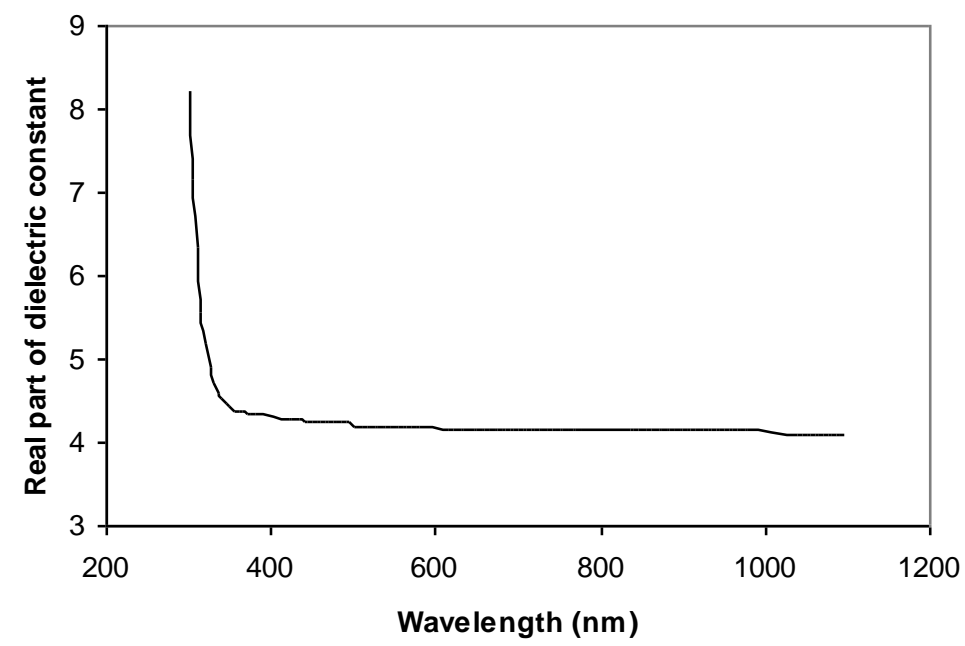

Fig. 15: The real parts of dielectric constant for sample1 thin film 


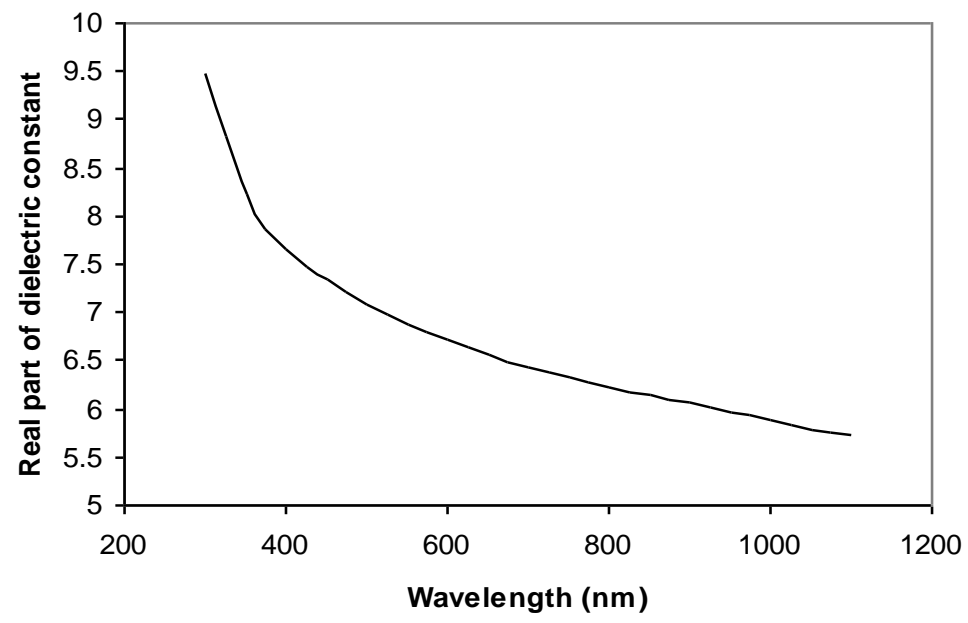

Fig. 16: The real parts of dielectric constant for sample2 thin film

Figures $(17,18)$ show the imaginary part of dielectric constant of different reaction condition.

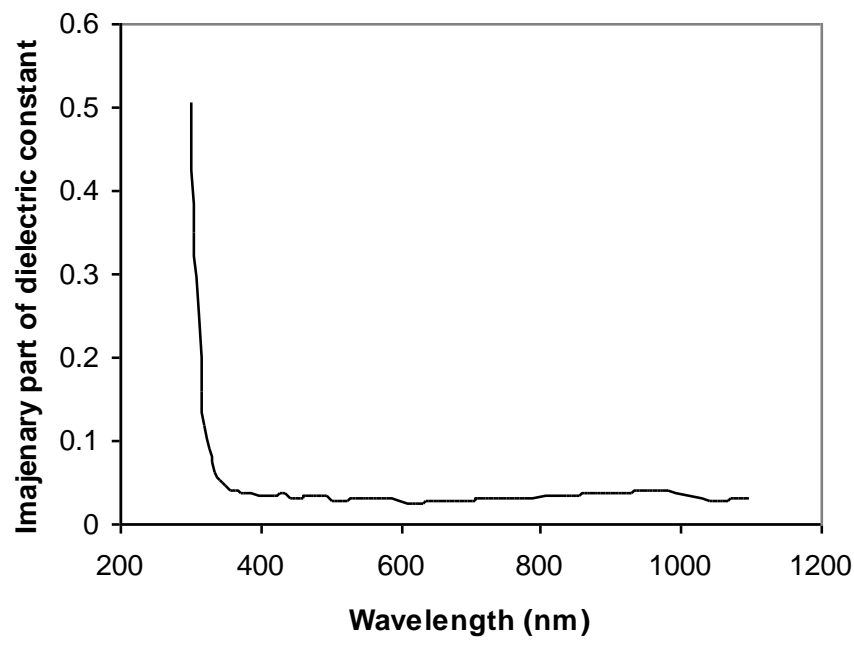

Fig. 17: The imaginary parts of dielectric constant for sample1 thin film

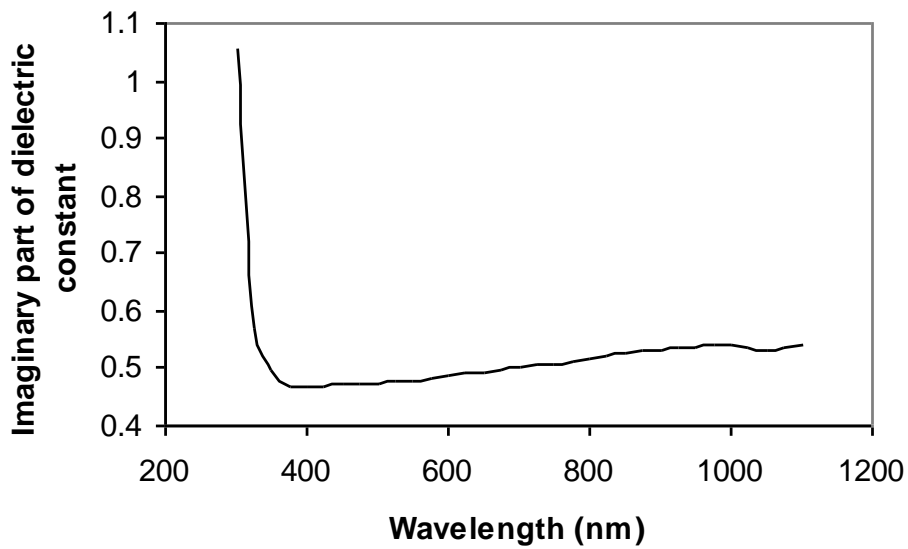

Fig. 18: The imaginary parts of dielectric constant for sample2 thin film 


\subsection{Photoluminescence Study}

PL measurements then yielded information about band gap energies of nanostructures that can be tuned by varying their sizes and the energetic positions of the electronic states in the band gap. On the other hand, wide band gap semiconductors are ideal materials for studies on trap states. Such localized states can be due to various types of imperfections like vacancies, interstitial atoms and dangling bonds. Bulk ZnS has a wide direct band gap of 3.68 eV. The large exciton binding energy $(40 \mathrm{meV})$ is much higher than thermal energy at room temperature ( 26 meV), the band edge $\mathrm{PL}$ of $\mathrm{ZnS}$ at room temperature is observed in high quality crystal [25].

The photoluminescence spectrum measured at room temperature of ZnS nanocrystalline thin films deposited on glass substrate as shown in (Figures.19,20).In figures show that two peaks positioned are around $361 \mathrm{~nm}$ and $489 \mathrm{~nm}$ for sample1 while $364 \mathrm{~nm}$ and $493 \mathrm{~nm}$ for sample2. Usually for semiconductor nanocrystals, two emission peaks can be observed, the exciton and the trapped luminescence. The exciton emission peak is sharp and the trapped emission is broad [26] The emission bands showed in the spectra can be attributed to band gap emission and the strong band gap emission demonstrates the high crystalline nature of the as-synthesized particles.

The emission at 489 and $493 \mathrm{~nm}$ may be caused by the transition from the conduction band to the zinc vacancies $V_{Z n}$ level (this localized vacancy level is above the valence band at $1.1 \mathrm{eV}$ ). The peaks at 361 and $364 \mathrm{~nm}$ can indicate exciton recombination [25] .Our results are agreed with [27].

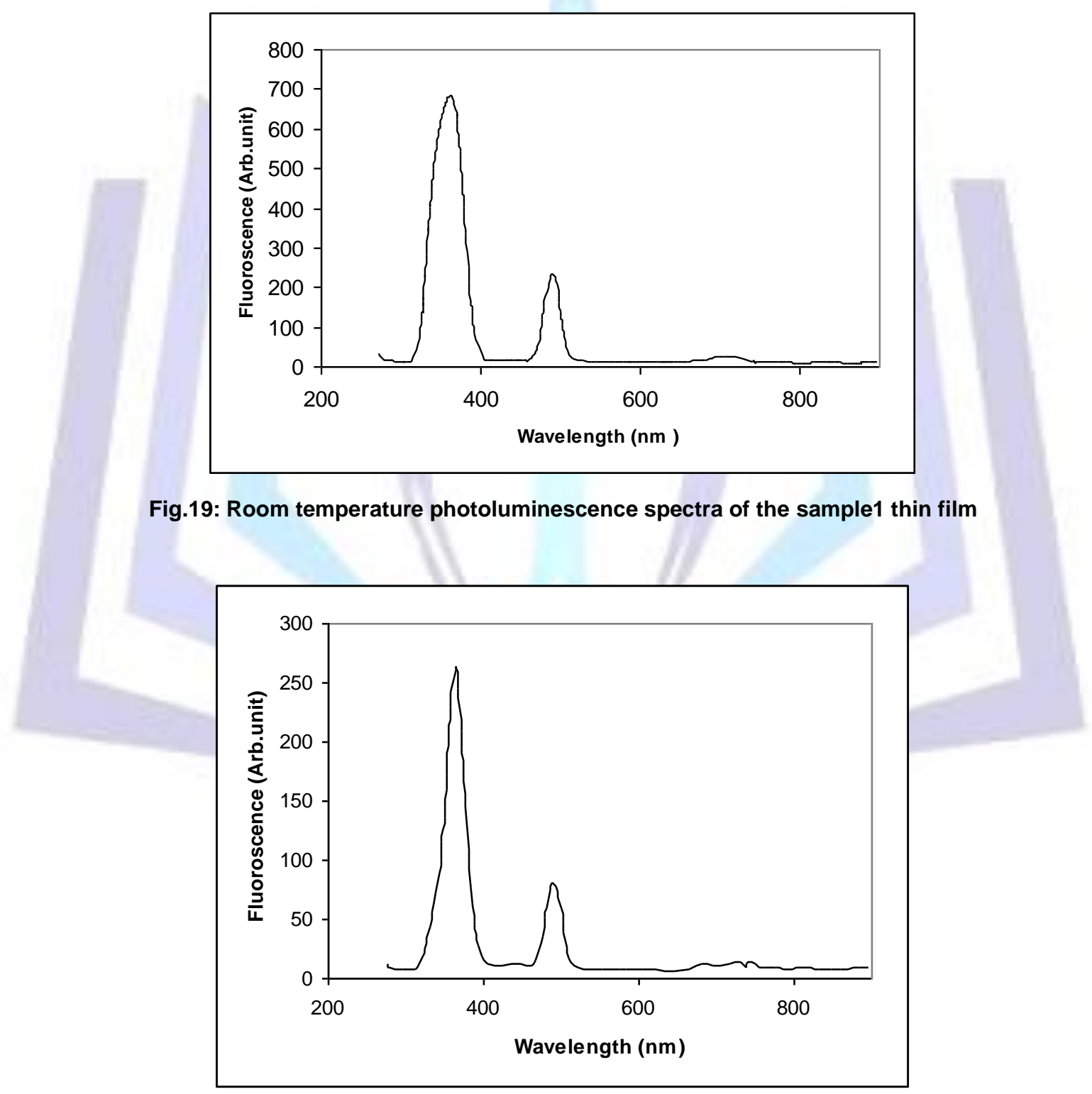

Fig. 20: Room temperature photoluminescence spectra of the sample2 thin film

We observed from (Figures 19, 20) that there were shift between the peaks of the two samples, that's may be attributed to different between band gaps for samples. 


\section{CONCLUSIONS}

Zinc sulfide nanocrystalline thin films were successfully deposited onto glass substrate by using chemical bath deposition technique with different reaction condition. The films have a good optical transparency for samle1; it was about $95 \%$ in the visible region, so it can be used as a transparent dielectric material. The prepared films have wide direct energy gap, the wide band gap makes these films good material for optoelectronic devices such as a window layer in photovoltaic cells.

\section{REFERENCE}

[1] Liu, Y., Zhan, J., Ren, M., Tang, K., Yu, W., Qian, Y., 2001, "Hydrothermal synthesis of square thin flake jmn ,CdS by using surfactants and thiocarbohydrate", Mater. Res. Bull., 36 (2001) 1231-1236.

[2] Yang, Q., Wang, K., C., Zhang, D., Qian , Y., "The synthesis of SnS 2 nanoflakes from tetrabutyltin precursor", J. Sol. State Chem., 164 (2002) 106-109.

[3] Wang, Y., Ma, C., Sun, X. H., Li, "Preparation of nanocrystalline metal oxide powders with the surfactant - mediated method", Inorg. Chem. Comm., 5 (2002) 751-755.

[4] Benavente, E. M., Santa Ana A, Mendizabal , F., Gonzalez G, "Intercalation chemistry of molybdenum disulfide", Coord. Chem. Rev., 224 (2002) 87-109.

[5] Borah, J.P., Barman, J. and Sarma ,K.C., "Structural and optical properties of ZnS nanoparticales", Chalcogenide Letters, 5 (2008) 201- 208.

[6] Li-li ,W., Jin-bo, Z. Ke, Yuan-chang, Z., S. and You-shi , W. , " Controllable morphologies of ZnO nanocrystals and the photoluminescence property' , Journal of Synthetic Crystals, 38(2009) 689-692.

[7] Wen-de, C. and Ping, W., " Synthesis and strong blue light emission properties of ZnO tetrapod nanostructure", Chinese Journal of Luminescence, 27(2006) 608-613.

[8] Hong-yan, X. , Xiu-lin, L. , . De-liang ,C, . Mei, L, Qi-long, W. and Min-hua, J., "Study on thick film gas sensors fabricated by using ZnO nanopowder", Journal of Functional Materials and Devices, 11(2005) 241-245.

[9] Dimos, K., Koutselas, I. B. and Karakassides, M.A, "Synthesis and characterization of ZnS nanosized semiconductor particles within mesoporous solids", The Journal of Physical Chemistry B, 110(2006) 22339-22345.

[10] Dhas N. A, Zaban , A. and Gedanken ,A. 1999. "Surface synthesis of zinc sulfide nanoparticles on silica microspheres: sonochemical preparation, characterization, and optical properties", Chemistry of Materials, 11(1999) 806-813.

[11] Wang, L. P. and Hong, G. Y. 2000. " A new preparation of zinc sulfide nanoparticles by solid-state method at low temperature", Materials Research Bulletin, 35(2000): 695-701.

[12] Zhao, Z. G., Geng ,F. X., Cong, H. T., Bai ,J .B. and Cheng , H. M. 2005 ."A simple solution route to controlled synthesis of ZnS submicrospheres, nanosheets and nanorods", Nanotechnology, 17(2006) 4731-4735.

[13] Chai , L. L., Zhu, Y. C., Du , J. , Zou,G. F. and Qian , Y.T. 2005. " One-step hydrothermal method to synthesize selfencapsulated ZnS micron core-shell spheres on a large scale", Chemistry Letters, 34 (2005) 1324-1325.

[14] Kolba ,D. M., Ullmanna ,R. and Zieglera,J.C.1998, " Electrochemical nanostructuring , Electrochimica Acta", 43(1998) 2751-2760.

[15] Ubale.. A. U., Sangawar V. S and Kulkarni, D. K. 2007. " Size dependent optical characteristics of chemically deposited nanostructured ZnS thin films, Bull. Mater. Sci., 30, ( 2007) 147-151.

[16] Shinde M. S., Ahirrao P. B., Patil , R. S. 2001 "Structural, Optical and Electrical Properties of Nanocrystalline ZnS thin films Deposited by Novel Chemical Route, Archives of Applied Science Research, 3 ( 2011) 311-317.

[17] Nabiyouni, G., Sahraei, R. , Toghiany, M., Majles M. H. and Hedayati, K. 2011. "Preparation and characterization of nanostructured ZnS thin films grown on glass and n-type Si substrates using anew chemical bath deposition technique" , Rev.Adv.Mater.Sci. 27(2011) 52-57.

[18] Longhurst, R.S. 1957. Geometrical and Physical Optics, Longmans Green, London.

[19] cottrell, A. 1975. Intorduction to Mettallurgy ,Arnold, Londan, P.173

[20] Bo, J., rah, .P. and Sarma, K.C. 2008." Optical and Optoelectronic Properties of ZnS Nanostructured Thin Film", ACTA PHYSICA POLONICA A, 114 (2008) 713-719.

[21] Tiwari, A., Khan, S .A. and Kher, R. S. 2011. "Advances in Applied Science Research" , 2 (2011) 105-110.

[22] Moss, T.S. 1986. "Infrared Physics" 26, 5, (1986) 335-336. 
[23] Liu, X. , Cai, X., Mao, J., and Jin,C. 2001. "ZnS/Ag/ZnS nano-multilayer films for transparent electrodes",. Appl. Surf. Sci. ,183(2001) 103-110.

[24] Hariskos, D., Spiering, S., and Powalla, M.2005. "Buffer layer in Cu(In)Se solar cell and mo dules", Thin Solid Films. 480,( 2005) 99-109.

[25] Üzar, N. and Arikan, M. 2011. "Synthesis and investigation of optical properties of ZnS nanostructures", Bull. Mater. Sci., 34, (2011), 287-292.

[26] John ,R., Florence, S. 2010. " Optical, structural and morphological studies of beanlike ZnS nanostructures by aqueous chemical method", Chalcogenide Letters , 7(2010). $269-273$.

[27] Kurbatov, D., Opan ,A., Kshnyakina ,S., Melnik, V.and Nesprava, V. 2010. " Luminescent and optical characteristics of zinc sulfide thin filoms produced by close-spaced vacuum sublimation" , Rom. Journ. Phys., 55(2010) $213-219$.

\section{Authors' information}

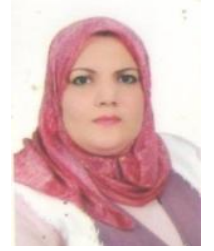

Professor Nada Khdair Abbas, Ph.D. in the Department of Physics, College of Science for Women, University of Baghdad .She had awarded the B.Sc. degree from the department of physics in 1986 , M.Sc. in 1995 and Ph.D. in 2000. teaching Students of under and post graduate, Chief of solid and materials group, Chairperson of the Committee promotions in the college of Science for women. She interested with research about Nanotechnology, the thin films and their use in solar cells and detectors.

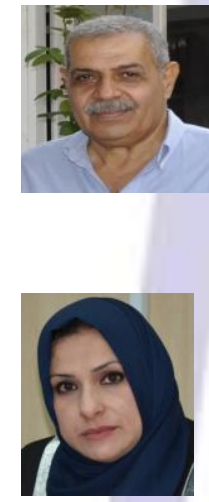

Professor Khalid T. Al- Rasoul, Ph.D. in the Department of Physics, College of Science, University of Baghdad. Teaching Students of under and post graduate. She interested with research about Nanomaterials and solar cells

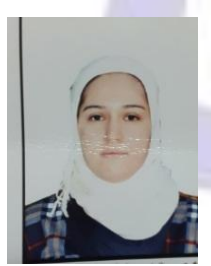

Dr.Zainab Jassim Shanan, Ph.D. in theDepartment of Physics, College of Science for Women, University of Baghdad .She had awarded the B.Sc. degree from the department of physics in 1995, M.Sc. in 2002 and Ph.D. in 2014. Teaching students of under graduate. She interested with research about Nanotechnology, the thin films and their use in solar cells and detectors.

Neean F.Mageed: was born in Baghdad in 1989 .She had awarded the B.Sc. degree from the department of physics, College of Science for Women, University of Baghdad in the year 2009/2010. She works as assistant of physicist in college of science for women, physics department, Baghdad University. She interest in field of solid materials and nanotechnology research 